\title{
Evaluation of Fetal Echocardiography as Antenatal Diagnostic Tool in Detection of Congenital Heart Diseases
}

\author{
Lamees Mohamed Ghith", Rania Essam-El-Dein Mohamed Ali, Emad Mohamed Mashaly, \\ Alshaimaa Zakarya Elshahawy
}

Radio-diagnosis \& Medical Imaging Department, Tanta University, Tanta, Egypt

Email address:

Lames_ghith@yahoo.com (L. M. Ghith)

${ }^{*}$ Corresponding author

\section{To cite this article:}

Lamees Mohamed Ghith, Rania Essam-El-Dein Mohamed Ali, Emad Mohamed Mashaly, Alshaimaa Zakarya Elshahawy. Evaluation of Fetal Echocardiography as Antenatal Diagnostic Tool in Detection of Congenital Heart Diseases. International Journal of Medical Imaging. Vol. 8, No. 4, 2020, pp. 72-83. doi: 10.11648/j.ijmi.20200804.12

Received: September 25, 2020; Accepted: October 10, 2020; Published: October 30, 2020

\begin{abstract}
Congenital heart diseases (CHDs) are one of the most common fetal malformations; the aim of the present study was to assess the role of fetal echocardiography in diagnosis of CHDs. The prenatal diagnosis of CHDs has been shown to have a significant effect on prenatal and postnatal management and outcomes. The current prospective study included 80pregnant women; detailed fetal echocardiography was performed according to International Society of Ultrasound in Obstetrics and Gynecology (ISUOG) guidelines [1]. In this study the range of gestational age was between $20-35$ weeks, $(57.5 \%)$ were males and $(42.5 \%)$ were females, 48 CHDs $(60 \%)$ were detected in the low risk group and $32(40 \%)$ were found in the high risk group, we found the most frequent risk factors for CHDs was positive parental consanguinity in (18 cases), multiple risk factors were found in (14 cases), there was insignificant correlation between mother age, fetal age and presence of risk factors. Our results showed that $20 \%$ of cases had associated ECAs, while $80 \%$ of cases had no associated ECAs. The most frequent CHDs encountered in our study was isolated VSDs (10\%). Complete agreement was found in (85\%) of cases between prenatal and postnatal echo findings. It is concluded that due to the high frequency of CHDs within the low risk pregnant females, we suggest that basic fetal echocardiography should be done for all pregnant women regardless the presence of risk factors.
\end{abstract}

Keywords: Fetal Echocardiography, Congenital Heart Diseases, Prenatal, Low Risk, Risk Factors

\section{Introduction}

Fetal echocardiography is defined as a detailed sonographic evaluation that is used to identify and characterize fetal cardiac anomalies prenatally; it has evolved considerably over the past 1-2 decades into an exciting field that bridges maternal-fetal medicine with neonatology and pediatric cardiology [2].

CHDs are the most common fetal malformations with incidence of four to eight cases per 1,000 live births being responsible for $20 \%$ of neonatal mortality and $50 \%$ of the deaths in infants [3].

Prenatal diagnosis of CHDs has been shown to have a significant effect on prenatal and postnatal management and outcomes, it also lead to additional testing of the fetus, including genetic evaluation and other anatomic imaging, which can yield valuable information in overall assessment of the fetus, which allows families to make informed decisions regarding the pregnancy and to prepare emotionally for the birth of a child with significant CHDs [4].

There are a number of indications for fetal echocardiography which may be maternal, fetal or familial, the maternal indications include gestational diabetes mellitus (DM), connective tissue diseases, such as Sjogren's syndrome and systemic lupus erythromatosus (SLE), assisted reproductive technology and use of drugs as antipsychotics and anti-epileptics drugs, the fetal indications are thickened nuchal translucency, other structural fetal anomalies, fetal infection [5], Familial indications include history of cardiac structural abnormalities of the parents' heart, history of cardiac anomalies in previous children and parental 
consanguinity [6].

Prenatal detection accuracy has varied widely for CHDs, some of this variation can be attributed to examiner experience, maternal obesity, transducer frequency, abdominal scars, gestational age, amniotic fluid volume, and fetal position [7].

The aim of this study is to assess the role of fetal echocardiography in diagnosis of CHDs.

\section{Patients and Methods}

This prospective study was carried out in the period from June 2017 to June 2019, on 80 consecutive pregnant women who were referred from gynecology and obstetrics department to Radio diagnosis and Medical Imaging Department to scan for fetal anomalies generally and structural cardiac anomalies especially. The study was approved by the Research Ethical Committee.

\subsection{Inclusion Criteria}

1. Pregnant women with gestational age from 18 weeks to 28 weeks of gestation referred for routine second trimester anomaly scan.

2. Special emphasis on high risk factors like CHDs in one of the parents, family history of CHDs, previous child with CHDs, maternal DM, mother on anti-epileptic drugs, maternal collagen diseases, increased nuchal translucency in first trimester ultrasound, polyhydramnios, oligohydramios and intrauterine growth restriction (IUGR).

\subsection{ExclusionCriteria}

Lethal fetal congenital anomalies that requires termination of pregnancy.

\subsection{Every Patient Was Subjected to the Following}

\subsubsection{Proper History Taking}

Patient data and written informed consents were obtained from all patients after full explanation of benefits. Privacy of all patients' data was guaranteed and there was a code number for every patient's file that includes all investigations and data.

\subsubsection{Ultrasound Examination}

All patients were scanned by two-dimensional transabdominal probe with a convex abdominal transducer (3-5 MHz.)

i. Fetal Biometry, Assessment of the Amniotic Fluid and Placenta

1) Fetal biometry was done by measurements of BPD, $\mathrm{HC}, \mathrm{AC}, \mathrm{FL}$ and TCD and then assessment of the fetal weight.

2) Amniotic fluid was assessed either by estimation of the amniotic fluid index (AFI) or measurement of a single maximal vertical pocket (MVP), oligohydraminos was diagnosed if AFI less than $5 \mathrm{~cm}$ or MVP less than $2 \mathrm{~cm}$ and polyhydramions was diagnosed if AFI equal to or greater than $25 \mathrm{~cm}$ or MVP equal to or greater than $8 \mathrm{~cm}$.

ii. Second trimester anomaly scan was performed including examination of fetal head, CNS, fetal lips, nose, orbits, neck, chest, extremities, stomach, kidneys, urinary bladder, umbilicus and two umbilical arteries.

iii. Detailed Fetal Echocardiography Was Performed as Follow

1) Determining the abdominal situs.

2) Transverse view of the abdomen.

3) Four chamber view; both apical and transverse views were examined.

4) Left ventricular outflow tract.

5) Right ventricular outflow tract

6) Three-vessel view.

7) Three vessel tracheal view (transverse view of the aortic and ductal arches).

8) Extended cardiac examination: Longitudinal views (Bicaval, aortic and pulmonary arches views) were done in selected cases which show anomalies of the aorta and pulmonary arteries or superior vena cava.

9) Color and pulsed Doppler US was complementary done for confirmation of the cardiac anomalies associated with flow abnormalities.

10) Any deviation from the normal appearance of the fetal heart or an unsatisfactory (inability to establish normal anatomy) cardiac views were considered indications for another session of detailed fetal echocardiography at any stage of pregnancy.

11) Abnormal or suspicious findings and its implication were discussed with the parents immediately. The aims of prenatal counseling were providing a clear and truthful picture of prognosis, outlining management and treatment options that are available, and helping parents reach decisions concerning the form of management that is best for them.

12) Postnatal cardiac examination of the neonates was performed and registered by a pediatrician.

13) Postnatal echocardiography was done for all neonates to confirm our prenatal diagnosis.

\subsection{Statistical Analysis}

Data were analyzed using IBM SPSS software package version 20.0. (Armonk, NY: IBM Corp) Qualitative data were described using number and percent. Quantitative data were described using range (minimum and maximum), mean, standard deviation and median, the used tests wereChisquare, Fisher's Exact, Student t-test and Kappa tests ( $\kappa)$.

\section{Results}

In the present study 80 pregnant patients were included, the maternal age ranged from 18 to 39 years with the mean of age was $26.80 \pm 5.70$ years, $42.5 \%$ of cases ranged between $18-25$ years, $37.5 \%$ of cases ranged between $25-35$ years. On the other hand, the maternal age ranged from 35-45 years 
was observed in $20 \%$ of cases.

Concerning to the maternal obstetric history, most of pregnant females, 54 cases $(67.5 \%)$ were multi-gravida, while 26 cases $(32.5 \%)$ were primi- gravida.

According to the risk factors for CHDs, 48 CHDs were detected in the low risk group and 32 were found in the high risk group. The incidence of prenatally diagnosed CHDs in our study was 40 and 60 per 1,00 high and low risk pregnancies respectively.

In the present study 14 pregnant females $(17.5 \%)$ had multiple risk factors, 6 cases $(7.5 \%)$ had previous baby with CHDs, in 16 cases (20\%) the risk factor was diagnosis of extracardiac anomalies, however 12 cases $(15 \%)$ of them had additional risk factors to the extra-cardiac anomalies, 4 cases (2.5\%) had gestational diabetes and 18 cases $(22.5 \%)$ had positive consanguinity, 14 cases of them had another risk factors.

According to the amniotic fluid index (AFI) in this study, 4 cases $(5 \%)$ showed increased amniotic fluid with AFI more than $25 \mathrm{~cm}$, while 8 cases $(10 \%)$ showed decreased amniotic fluid with AFI less than $5 \mathrm{~cm}$. Normal amniotic fluid index was found in 68 cases $(85 \%)$.

Regarding the distribution of the studied cases according to fetal gender, the current study showed that 46 fetuses $(57.5 \%)$ were males and 34 fetuses $(42.5 \%)$ were females.

The range of gestational age of the studied fetuses was 20 35 weeks with the mean gestational age was $27.45 \pm 4.76(\mathrm{SD})$

In this study most of the studied fetuses $(66 / 80 ; 82.5 \%)$ showed appropriate growth for GA, On the other hand, 10 fetuses $(12.5 \%)$ showed IUGR, in which two of them suffers from placenta insufficiency, four were associated with extracardiac anomalies and chromosomal abnormalities and the last four fetuses were just small for GA, 4 fetuses (5\%) were large for GA whose mothers had gestational DM.

From 80 cases, $16(20 \%)$ cases had associated ECAs while $64(80 \%)$ cases had no associated ECAs.

Regarding the mode of delivery in the current study, 36 cases $(45 \%)$ underwent normal vaginal delivery, while 44 cases $(55 \%)$ were delivered by cesarean section,

As regard the fetal situs, 72 fetuses $(90 \%)$ were situs solitus, 8 fetuses $(10 \%)$ were situs ambiguous (left atrial isomerism) while no fetuses with situs inversus were encountered in this study. On the other hand the cardiac axis was levocardia in 74 fetuses $(93.5 \%)$, while it was dextrocardia in 6 fetuses $(7.5 \%)$, two of them was isolated dexrocardia without associated complex cardiac anomalies, the other four cases were associated with other cardiac anomalies, No cases of mesocardia were found in our study.

In the present study, there was insignificant statistically relation between mother age and presence of risk factors ( $\mathrm{p}$ value $=0.497$ ) and also the relation was insignificant between fetal gestational age and risk factors ( $p$-value $=0.392$ ).

Septal defects (including ventricular septal defect, atrial septal defect and atrio-ventricular septal defects), hypoplastic heart syndrome (including right \& left sides), conotruncal anomalies (including tetrology of fallot (TOF), double outlet right ventricle (DORV), transposition of great arteries (TGA) and common arterial trunk (CAT)), situs abnormalities with complex cardiac anomalies, vulvular diseases (in the form of pulmonary atresia, tricuspid dysplasia and pulmonary stenosis), cardiac masses (single \& multiple rhabdomyomas) and extracardiac vascular anomalies (isolated persistent left SVC \&right sided aortic arch), Other unspecified cardiac anomalies (in the form of minimal pericardial effusion \&isolated dextrocardia) were observed in our study as different types of congenital heart diseases. the most common cardiac anomaly encountered in the study was isolated VSD which was detected in 8 cases out of $80(10 \%)$. The second most frequent CHD detected was dysplastic tricuspid valve with tricuspid regurgitation which was found in 6 fetuses $(7.5 \%)$.

We found complete agreement of $85 \%$ of diagnosed cardiac anomalies between prenatal and postnatal echo findings.

Table 1. Distribution of the studied cases according to maternal age $(N=80)$.

\begin{tabular}{|c|c|c|c|c|}
\hline Age (years) & $\begin{array}{l}18-<25 \\
(n=34)\end{array}$ & $\begin{array}{l}25-<35 \\
(n=30)\end{array}$ & $\begin{array}{l}35-<45 \\
(n=16)\end{array}$ & $\begin{array}{l}\text { Total } 18-< \\
45\end{array}$ \\
\hline$\%$ & $42.5 \%$ & $37.5 \%$ & $20.0 \%$ & $100 \%$ \\
\hline Mean \pm SD. & $21.53 \pm 1.74$ & $28.0 \pm 2.20$ & $35.75 \pm 1.49$ & $26.80 \pm 5.70$ \\
\hline
\end{tabular}

Table 2. Distribution of the studied cases according to Gravidity $(N=80)$.

\begin{tabular}{lll}
\hline Gravidity & N & \% \\
\hline Primigravida & 26 & 32.5 \\
Multigravida & 54 & 67.5 \\
\hline
\end{tabular}

Table 3. Distribution of the studied cases according to risk factors $(N=80)$.

\begin{tabular}{lll}
\hline Risk factors & N & \% \\
\hline No & 48 & 60.0 \\
Yes & 32 & 40.0 \\
\hline
\end{tabular}

Table 4. Distribution of risk factors among the studied patients $(N=80)$.

\begin{tabular}{lll}
\hline Type of risk factors & N & $\mathbf{\%}$ \\
\hline No risk factors & 48 & 60 \\
Multiple risk factors & 14 & 17.5 \\
Previous baby with CHD & 6 & 7.5 \\
Positive family history of cardiac disease & 2 & 2.5 \\
Associated otherECAs & 16 & 20 \\
Gestational diabetes & 4 & 5 \\
Infection & 2 & 2.5 \\
Parental consanguinity & 18 & 22.5 \\
\hline
\end{tabular}

Table 5. Distribution of the studied cases according to amount of amniotic fluid $(N=80)$.

\begin{tabular}{lll}
\hline Amount of amniotic fluid & N & \% \\
\hline Normal & 68 & 85.0 \\
Oligohydraminos & 8 & 10.0 \\
Polyhydraminos & 4 & 5.0 \\
\hline
\end{tabular}

Table 6. Distribution of the studied cases according to fetal gender $(N=80)$.

\begin{tabular}{lll}
\hline Fetal gender & $\mathbf{N}$ & $\mathbf{\%}$ \\
\hline Male & 46 & 57.5 \\
Female & 34 & 42.5 \\
\hline
\end{tabular}


Table 7. Distribution of the studied cases according to fetal gestational age $(N=80)$.

\begin{tabular}{lll}
\hline Fetal Gestational age (weeks) & N & \% \\
\hline $17-<21$ weeks & 4 & 5.0 \\
$21-<27$ weeks & 32 & 40.0 \\
$27-<30$ weeks & 16 & 20.0 \\
$30-<34$ weeks & 16 & 20.0 \\
$34-<37$ weeks & 12 & 15.0 \\
Min. - Max. & $20.0-35.0$ & \\
Mean \pm SD. & $27.45 \pm 4.76$ & \\
\hline
\end{tabular}

Table 8. Distribution of the associated ECA anomalies within the studied cases $(N=80)$.

\begin{tabular}{|c|c|c|}
\hline Type of associated anomaly & $\mathbf{N}$ & $\%$ \\
\hline Bilateral hydro ureter and hydronephrosis associated with echogenic kidney & 2 & 2.5 \\
\hline Situs abnormalities & 6 & 7.5 \\
\hline Situs abnormalities and Ventriculomegally & 2 & 2.5 \\
\hline Ascites & 2 & 2.5 \\
\hline Dandy walker andPleural effussion & 2 & 2.5 \\
\hline Hypoplastic nasal bone and omphalocele & 2 & 2.5 \\
\hline No Extra-cardiac anomalies & 64 & 80 \\
\hline
\end{tabular}

Table 9. Relation between Risk factors with fetal Gestational age (weeks) and maternal age (years) $(N=80)$.

\begin{tabular}{|c|c|c|c|c|}
\hline \multirow{2}{*}{ Fetal and maternal age } & \multicolumn{2}{|l|}{ Risk factors } & \multirow[b]{2}{*}{$\mathbf{t}$} & \multirow[b]{2}{*}{$\mathbf{p}$} \\
\hline & No $(N=48)$ & Yes $(N=32)$ & & \\
\hline \multicolumn{5}{|c|}{ Fetal Gestational age (weeks) } \\
\hline Min. - Max. & $20.0-34.0$ & $20.0-35.0$ & & \\
\hline Mean \pm SD & $26.92 \pm 4.37$ & $28.25 \pm 5.34$ & 0.865 & 0.392 \\
\hline Median & 26.50 & 28.0 & & \\
\hline \multicolumn{5}{|l|}{ Maternal age (years) } \\
\hline Min. - Max. & $18.0-39.0$ & $20.0-35.0$ & & \\
\hline Mean \pm SD & $26.29 \pm 5.72$ & $27.56 \pm 5.76$ & 0.686 & 0.497 \\
\hline Median & 25.50 & 27.50 & & \\
\hline
\end{tabular}

$\mathrm{N}=$ number.

$\chi^{2}$ : Chi square test

$\mathrm{p}: \mathrm{p}$ value for association between risk factors with fetal and maternal age.

*: Statistically significant at $\mathrm{p} \leq 0.05$

Table 10. Distribution of the studied cases according to type of cardiac anomalies $(N=80)$.

\begin{tabular}{|c|c|c|}
\hline Type of cardiac anomaly & $\mathbf{N}$ & $\%$ \\
\hline Isolated VSD & 8 & 10 \\
\hline ASD & 2 & 2.5 \\
\hline AVSD & 4 & 5 \\
\hline Hypoplastic heart syndrome & 8 & 10 \\
\hline Malalignment VSD with overriding aorta & 6 & 7.5 \\
\hline TOF & 6 & 7.5 \\
\hline DORV & 6 & 7.5 \\
\hline CAT & 2 & 2.5 \\
\hline Situs abnormalities & 8 & 10 \\
\hline Pulmonary atresia & 2 & 2.5 \\
\hline Tricuspid dysplasia & 6 & 7.5 \\
\hline Cardiac masses & 4 & 5 \\
\hline Extracardiac anomalies & 4 & 5 \\
\hline Minimal pericardial effusion & 2 & 2.5 \\
\hline Pericardial effusion with cardiomegally & 2 & 2.5 \\
\hline
\end{tabular}

Table 11. Agreement between pre and postnatal US findings $(N=80)$

\begin{tabular}{lll}
\hline Final diagnosis & N & \% \\
\hline Agreed & 68 & 85 \\
Not agreed & 12 & 15 \\
\hline
\end{tabular}



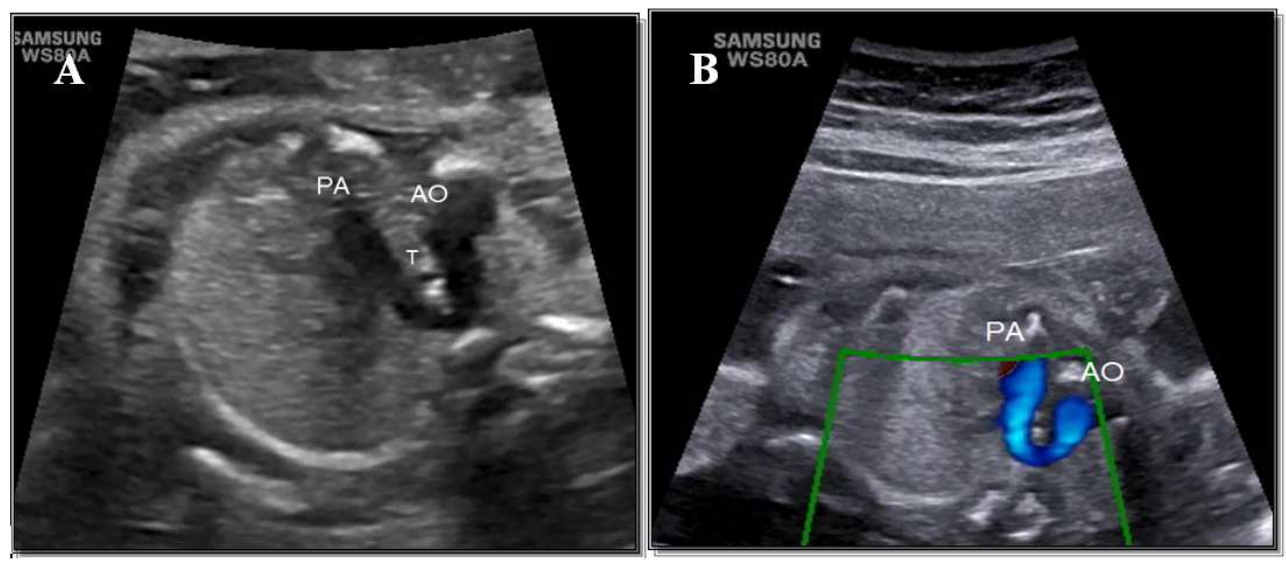

Figure 1. 27 years old pregnant lady, G4P3L3, GA=24weeks+1day, no history of medical disorder or cardiac anomalies in previous children. No consanguinity and no family history of cardiac disease.

(A) Three vessel trachea view: the trachea (T) is located between the aortic arch (AO) and the ductal arch (PA). (B) Color Doppler confirms the presence of the aortic arch (AO) on the right side of the trachea $(\mathrm{T})$ with retro-tracheal vessel is identified.

Diagnosis: Right sided aortic arch with retro-tracheal vessel (Aberrant left subclavian or left innominate artery).
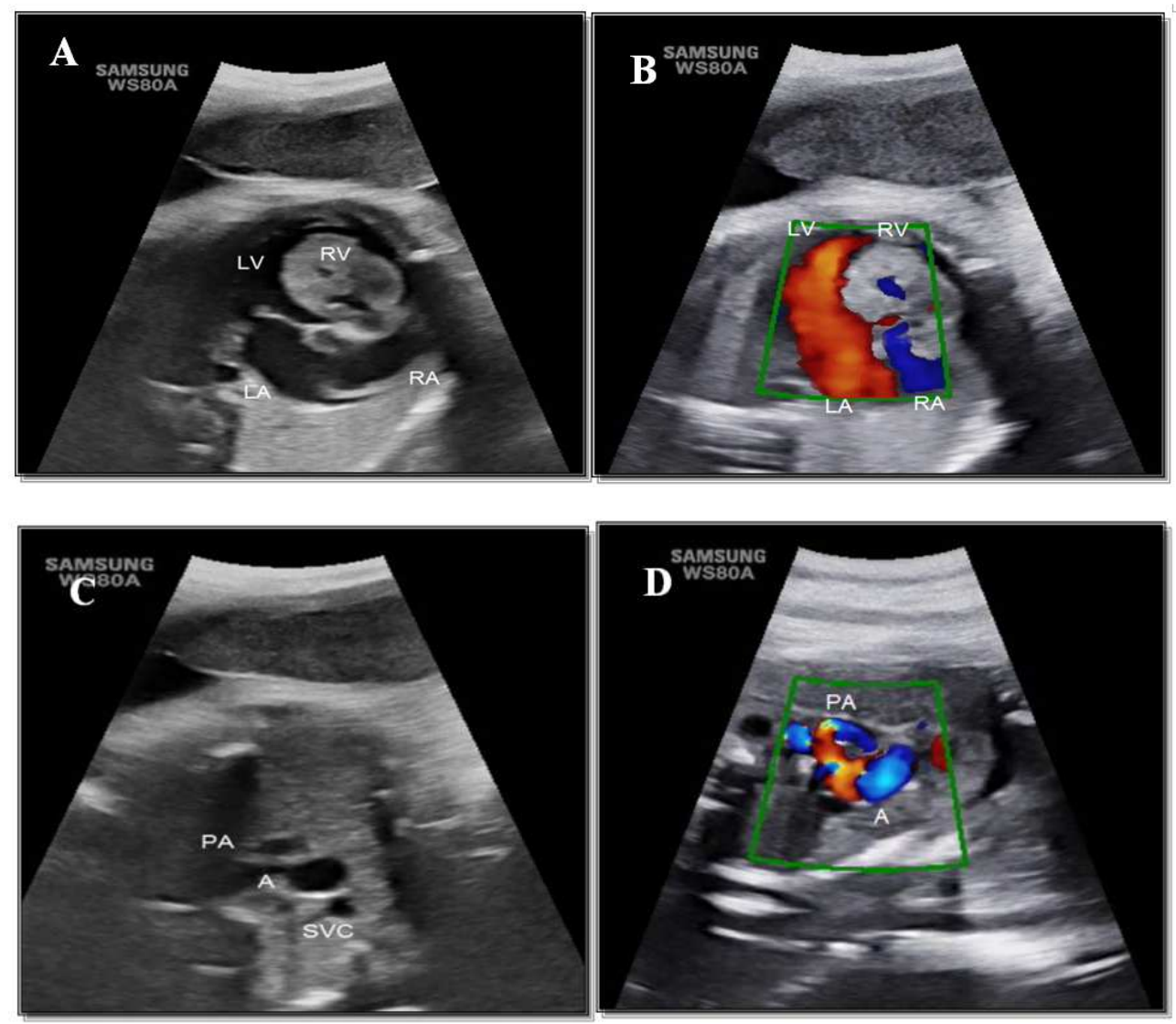

Figure 2. 33 years old pregnant woman, G5P4L3D1 GA=32 weeks +4 day, no history of medical disorder or cardiac anomalies in previous children. No consanguinity and no family history of cardiac disease.

(A and B): 2D US and color Doppler, Four chamber view show marked hypoplasia of the right ventricle (RV) with hypertrophy of its wall surrounded by pericardial effusion.

(C): Three vessel view shows small pulmonary artery (PA) relative to the aorta (A).

(D): Three vessel view with color Doppler, demonstrates retrograde flow in the PA across the dilated ductus arteriosus.

Diagnosis: Hypoplastic right heart syndrome. 

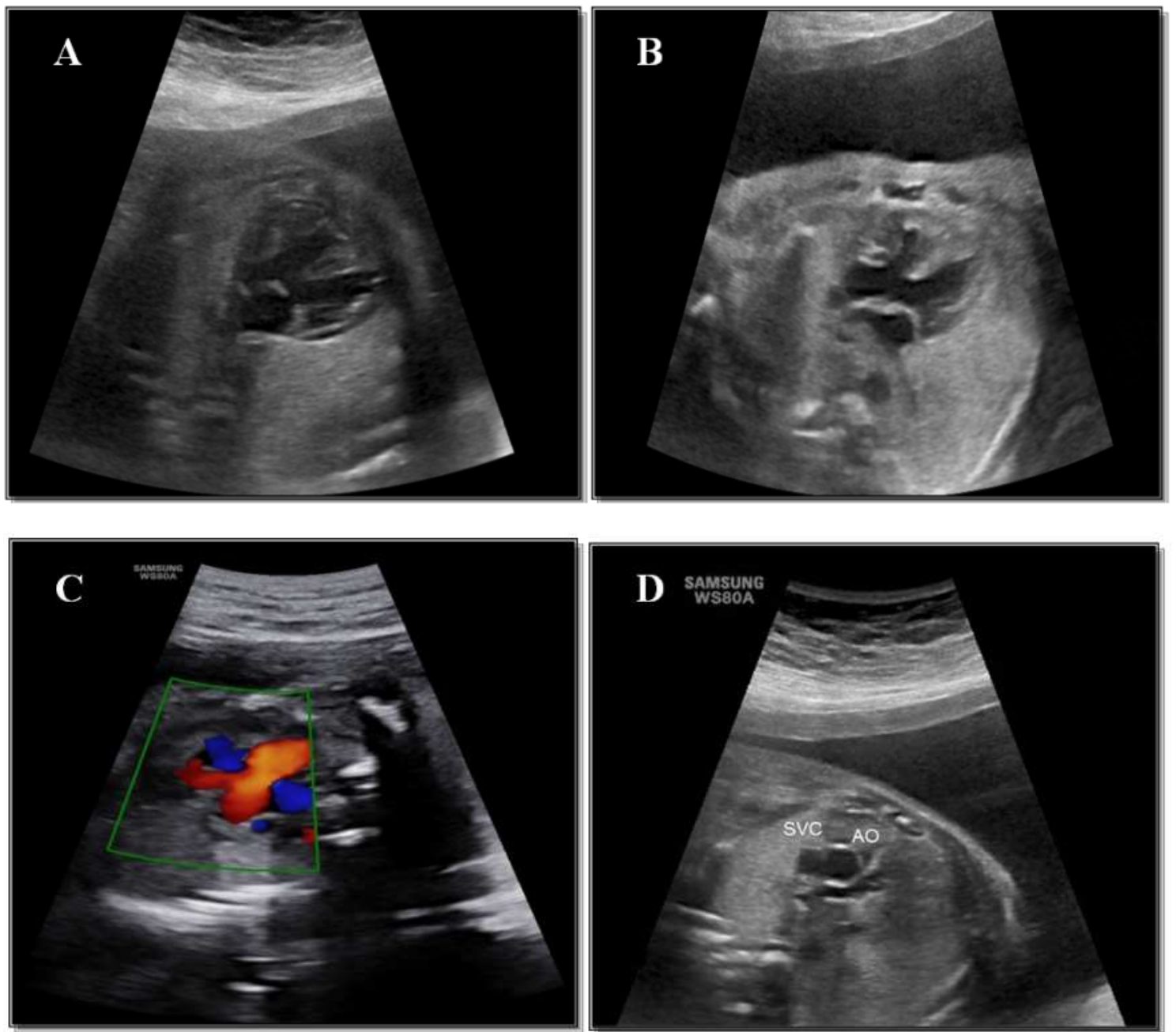

Figure 3. 34 years old pregnant lady, G5P3L3A1, GA=26 weeks+3days, no history of medical disorder or cardiac anomalies in previous children. Positive consanguinity and no family history of cardiac disease.

(A and B): Left outflow tract shows malalignment VSD with an overriding aorta. (C): On left outflow tract with color Doppler the overriding aorta draining both ventricles (Y sign). (D): 2D US three vessel view shows small sized pulmonary artery Diagnosis: Tetrology of Fallot.
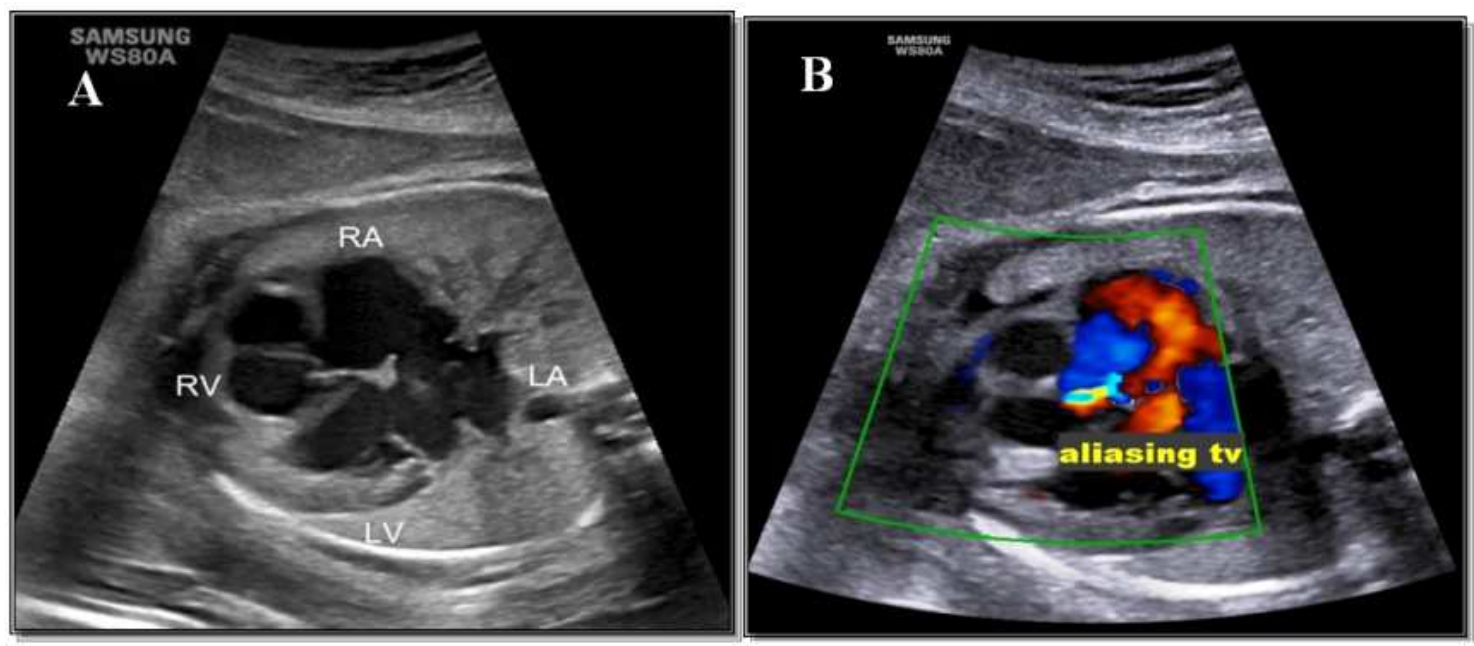

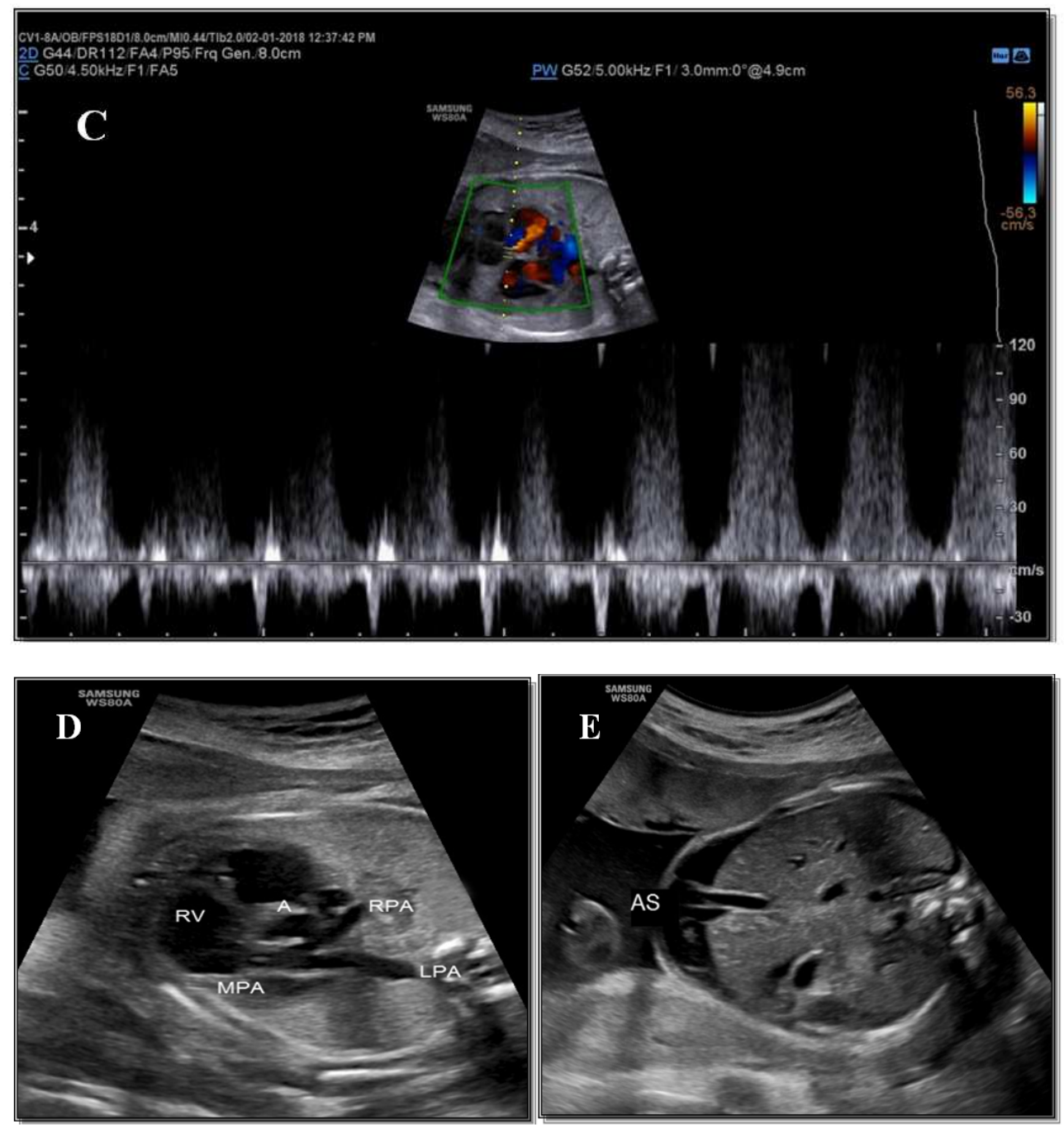

Figure 4. 31 years old pregnant lady, G3P2L2, GA=30 weeks+3days, no history of medical disorder, positive history of cardiac anomalies in previous child, positive consanguinity and no family history of cardiac disease.

(A): Four chamber view shows thickened and hyperechoic tricuspid valve leaflet.

(B): Four chamber view with color Doppler demonstrates the systolic regurgitation (aliasing flow) across the tricuspid valve.

(C): Color Doppler with spectral flow study confirms the regurgitation by detection of systolic wave across the tricuspid valve with PSV more than $(60 \mathrm{~cm} / \mathrm{s})$.

(D): Right ventricular outflow tract detects small size pulmonary artery (MPA) relative to the aorta (A).

(E): Axial view of fetal abdomen shows ascites (AS).

Diagnosis: Tricuspid dysplasia with pulmonary stenosis associated with ascites.
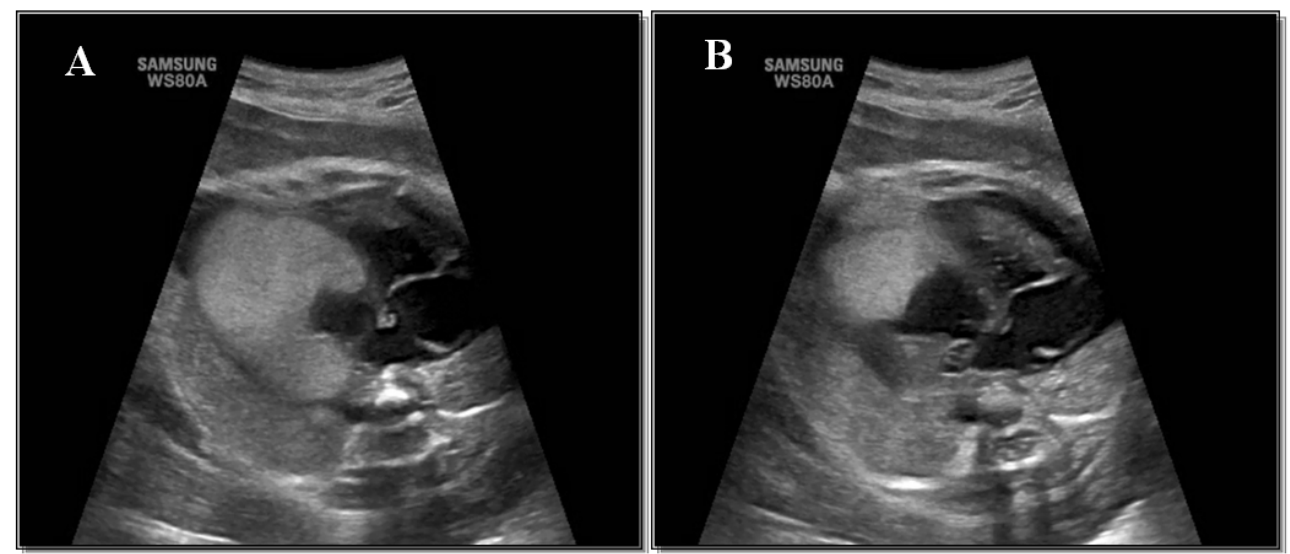


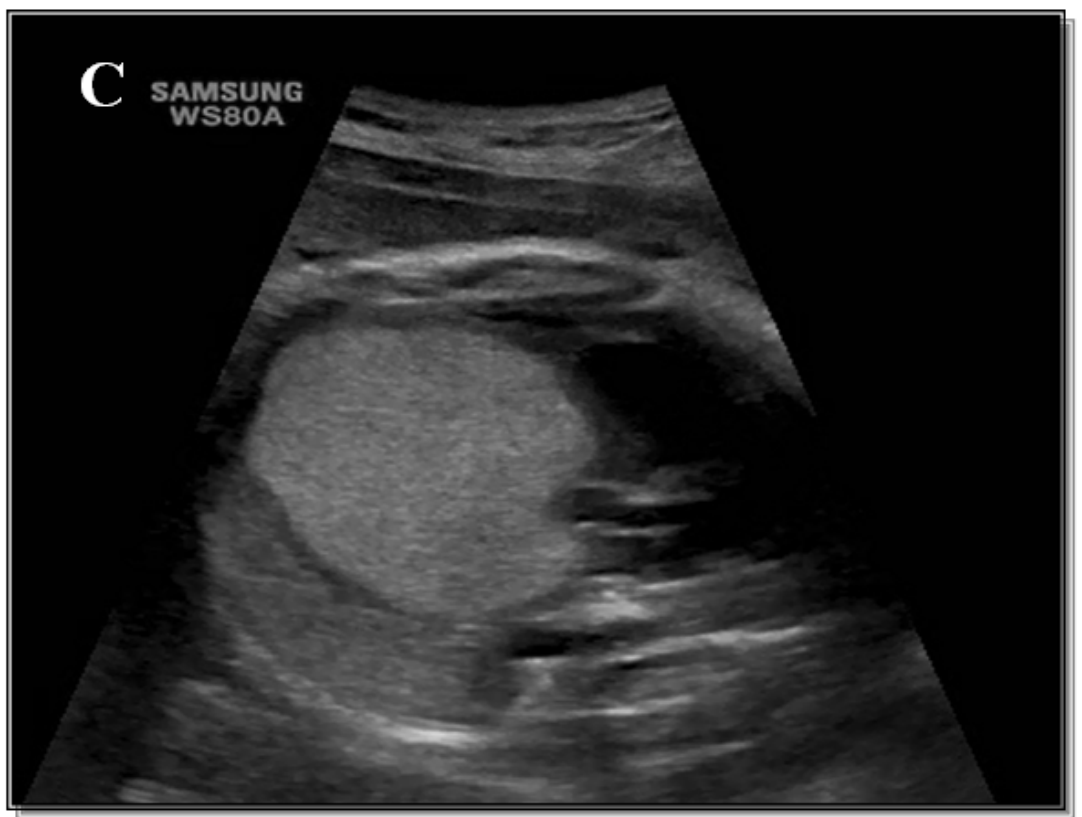

Figure 5. 31 years old pregnant lady, G3P2L2, GA=32 weeks+Oday, no history of medical disorder or cardiac anomalies in previous children. No consanguinity and no family history of cardiac disease.

(A-C): Four chamber view shows large hyperechoic exophtic soft tissue mass arising from the left ventricular wall and inter-ventricular septum associated with pericardial effusion in B.

Diagnosis: Single rhabdomyoma.
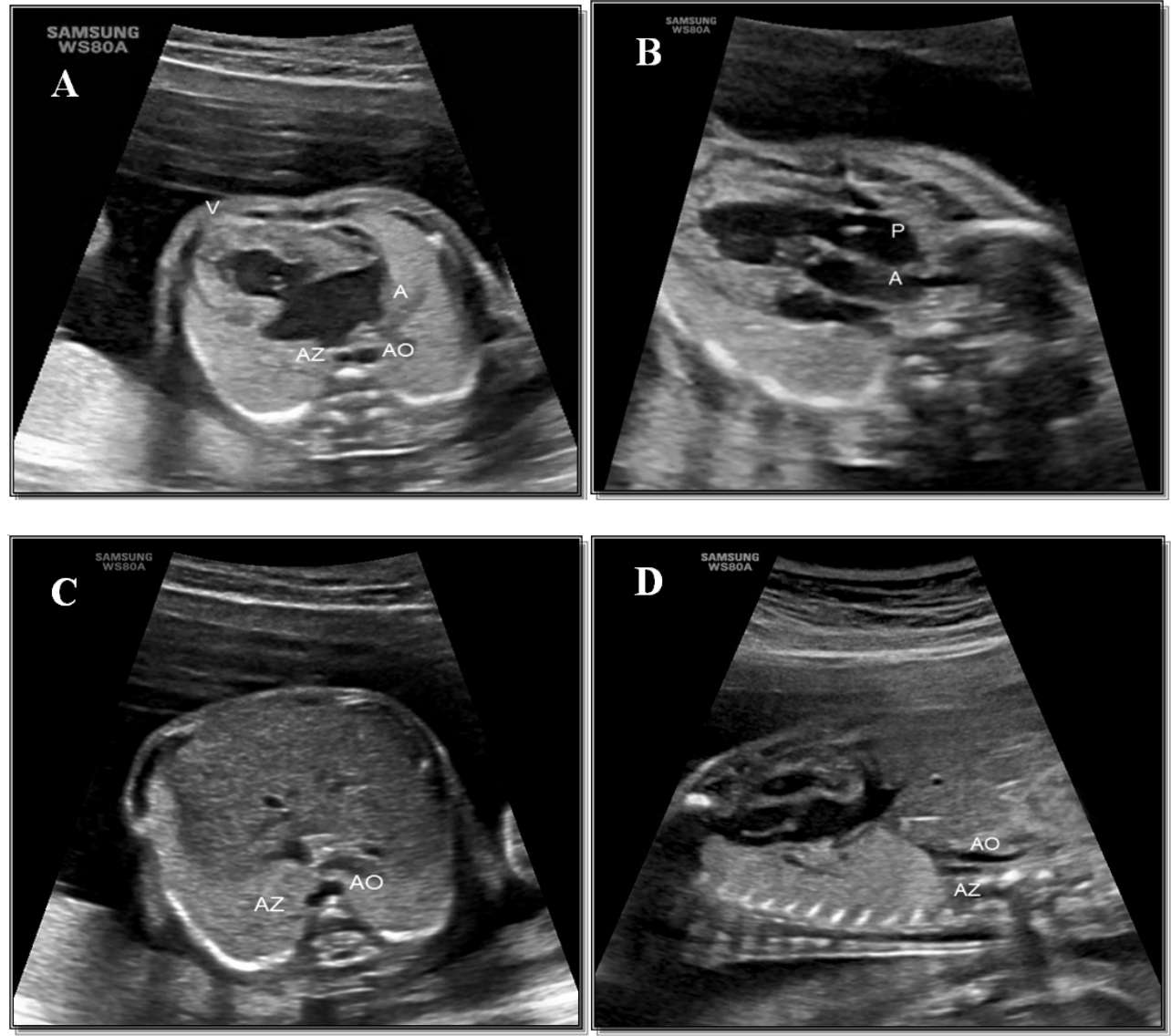


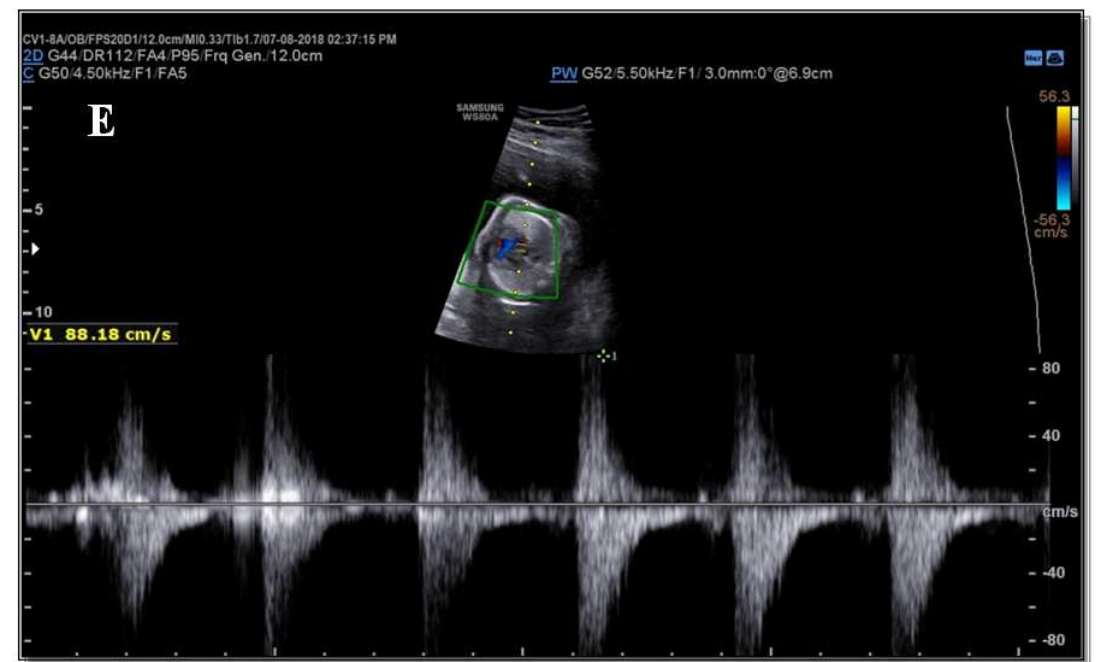

Figure 6. 20 years old pregnant lady, G1P0, GA=22 weeks+1day, no history of medical disorder. Positive consanguinity and no family history of cardiac disease.

(A): Four chamber view shows single atrium (A) and single ventricle (V) with hypertrophied wall, note the presence of two rather than one vessel, dilated azygos vein (AZ) adjacent to the descending aorta $(\mathrm{AO})$ behind the common atrium.

(B): Outflow tracts demonstrates the double outlet of both great vessels ( $\mathrm{P}$ and $\mathrm{A})$ from the single ventricle.

(C): Axial view of the fetal abdomen shows the dilated azygos vein (AZ) close and lateral to the descending aorta (AO).

(D): Para-sagittal view demonstrates the interruption of the intrahepatic segment of the IVC with azygos continuation (AZ) lateral to the descending aorta (AO).

(E): Color Doppler with spectral flow study of the pulmonary trunk shows the regurgitation across the valve by detecting high PSV (more than $60 \mathrm{~cm} / \mathrm{sec}$ )

Diagnosis: Left isomerism with common atrium and ventricle associated with pulmonary regurge.

\section{Discussion}

In the present study, The maternal age ranged from 18 to 39 years with mean of $26.8( \pm 7.37)$ years and median of 26 years, this was parallel to the results obtained by by Carvalho et al., 2002 [8], the mean maternal age of the study population was 27 years (range 15-44 years), Also Radi et al., 2018 [9] found that the mean age in their study was 28 $( \pm 5.34)$ years.

On contrary, Fernándezaet al., 2019 [10] found that the mean maternal age was above thirty years equal to $34 \pm 4.78$ years.

In the present study, the frequency of CHDs increases in multigravida more than primigravida, as we found that $(67.5 \%) 54$ out of 80 cases were multigravida while $(32.5 \%)$ 26 out of 80 cases were primigravida, This is in agreement with Perriyanayaki et al., 2016 [11] who found that the majority of cardiac anomalies were observed in multiparous women when compared with primigravida. Also, Sarkar et al., 2013 [12] found that there is positive association between the birth order and the incidence of congenital anomalies.

In the current study, the mean age of gestation at prenatal diagnosis of CHDs was ranged between $(20-35)$ weeks with mean GA $(27.45 \pm 4.76)$ weeks. This is in agreement with Pasierb et al., 2018 [13] study where there were 699 fetal seen for prenatal cardiology consultation with mean GA at initial consultation (26.5) weeks. Also, in Cha et al., 2012 and Radi et al., 2018 [14,9] studies, the mean GA at prenatal diagnosis was $(26.2 \pm 5.2)$ weeks in the former and (25) weeks in the later.

On the other hand, the mean age of gestation at prenatal diagnosis of CHDs was earlier in Meyer et al., 2001 [15] study in which the mean GA was $(23.8)$ weeks.

Out of 80 anomalies in our study, 46 fetuses $(57.5 \%)$ were males. This is in agreement with the study obtained by Tashfeen and Hamdi, 2013 [16] who found that male babies accounted for majority of the cases $(52.8 \%)$ with cardiac anomalies. On the other hand the studies were done by Aly and Abd-Manaf, 2013and Itsukaichi et al., 2018 [17, 18] found no significant difference in the frequency of congenital anomalies among male and female babies.

In our study, the mode of delivery in 36 cases (45\%) was normal vaginal delivery, while 44 cases $(55 \%)$ underwent lower scar cesarean section (LSCS), this is in disagreement with Sharmaet al., 2017 [19] study, where out of 13 cases, who were delivered live 9 cases $(69.5 \%)$ delivered by normal vaginal delivery and 4 cases $(30.5 \%)$ underwent LSCS.

In the current study we found that $60 \%$ (48 out of 80 cases) had no risk factors for CHDs and 40\% (32 out of 80 cases) had risk factors, so we stated that frequency of CHDs in low risk group is higher than high risk group, this results matched with Mottaghiet al., 2018 [6] who reported that there was significant difference in CHDs diagnosis between the high- and low-risk pregnancies, the incidence is high in the low risk group, Also, Nayaket al., 2016 [20] found that a high proportion of prenatally detectable cases of CHDs ( 24 of 26 cases) occurred in pregnant women with no risk factors. Moreover, Sharma et al., 2017 [19] reported that $61 \%$ of CHDs were detected in the low risk group and $39 \%$ were found in the high risk group, which is very close to our results.

On contrary, in Radi et al., 2018 [9] study $78.4 \%$ of patients had risk factors and $21.6 \%$ had no risk factors which 
is nearly similar to results of Perriyanayaki et al., 2016 [11] where (4 out of11 cases $(36.6 \%)$ ) of confirmed cardiac anomalies did not have any high risk factors.

The most frequent risk factors for CHDs in our study was positive parental consanguinity in (18 cases) then abnormal fetal sonogram in the form of detection of extra-cardiac associated anomalies in (16 cases), this findings are in agreement with the study obtained by El Hamid et al., 2015 [21] where highly statistically significant differences were found between consangious and non consangious marriage in relation to the incidence CHDs. Also, in Mottaghi et al., 2018 [6] the observation of sonographic abnormalities in the pregnant female referred by an obstetrician was one of the most frequent risk factors. But these results are in disagreement with Luciane et al., 2014 and Clur et al., 2011 $[22,23]$ who stated that the most common risk factor was maternal metabolic disease and increased nuchal translucency respectively.

Another results were reported by Cha et al., 2012 [14] who found among maternal or familial risk factors, the most common was a previous child with a CHDs.

Furthermore, in Plesinac et al., 2007 [24] study, the most frequent risk factor for CHDs was multiple gestations.

In the current study we found that there was insignificant correlation between mother age and presence of risk factors ( $p$-value 0.497), this finding is in agreement with the study obtained by Radi et al., 2018 [9] who found insignificant correlation between maternal age and risk factors ( $p$-value 0.494), there was also insignificant correlation between fetal age and presence of risk factors (p-value 0.392) in our study, this disagrees with results obtained by Zhang et al., 2011 [25] meta-analysis and Radi et al., 2018 [9] who found that the fetal age had significant effect on different anomalies.

The present study showed that $20 \%$ (16 out of 80 cases) had associated ECAs, our results are parallel to the results of Sharma et al., 2017 [19] study where $27 \%$ of their cases had associated ECAs. Also, Calzolari et al., 2003 [26] reported that $26 \%$ of cases of CHDs had associated ECAs. On the other hand higher incidence of association was reported by Perriyanayaki et al., 2016 [11] where $36 \%$ (4 out of 11 cases) had associated ECAs.

As regard the type of associated ECAs, our study showed that the most frequent associated anomaly is situs abnormalities and the second most frequent is CNS anomalies including ventriculomegally and Dandy Walker Quantinum. In Perriyanayaki et al., 2016 [11] the most common anomalies associated with the presence of cardiac anomaly are single umbilical artery, renal pyelectasis, Dandy Walker Quantinum and fetal ascites. However, in Sharma et al., 2017 and Calzolari et al., 2003 [19, 26] studies, the most frequent anomalies seen in association with CHDs were of musculoskeletal system (45.4\%).

The most common cardiac anomaly in the current study was isolated VSD which was found in 8 out of 80 anomalies $(10 \%)$, this figure is in good agreement with the studies done by Mottaghi et al., 2018, Sharma et al., 2017, Ozkutlu et al., 2010, Zhang et al., 2011 and Itsukaichi et al., 2018 [6, 19, 27,
$25,18]$ who reported the same result.

On contrary Radi et al., 2018, Perriyanayaki et al., 2016 and Nayak et al., 2016 [9, 11, 20] found that endocardial cushion defects (AVSD) are the most frequent anomalies in their studies. Furthermore, in the studies obtained by Cha et al., 2012 and Berkley et al., 2009 [14, 28], the most common cardiac anomaly among their cases was TOF.

The second most frequent cardiac anomaly in our study was dysplastic tricuspid valve with tricuspid regurgitation found in 6 out of 80 cases $(7.5 \%)$, this result is disconcordant with results of Perriyanayaki et al., 2016 [11] study where echogenic cardiac focus was the $2^{\text {nd }}$ most common anomaly and Sharma et al., 2017 [19] who reported that the $2^{\text {nd }}$ most frequent anomaly is endocardial cushion defects (AVSD).

On the other hand Radi et al., 2018, Cha et al., 2012 and Berkley et al., 2009 [9, 14, 28] stated that isolated VSD is the $2^{\text {nd }}$ common cardiac anomaly, however it was ASD in Zhang et al., 2011 [25] study.

In the current study, we found complete agreement of 68 out of 80 cases $(85 \%)$ between prenatal and postnatal echo findings while the remaining 12 cases $(15 \%)$ showed no agreement, this result is nearly similar to Vanvelzen et al., 2016 [29] study, where complete agreement between prenatal and postnatal diagnosis was $82.1 \%$

Also our results are in accordance with Sokołowski, 2013 [30] who found complete agreement between fetal and neonatal echocardiography in $31 / 35 \quad(88,6 \%)$ mothers. However, the results obtained by Plesinac et al., 2007 [24] show higher degree of agreement between fetal and neonatal echocardiography than in our study, it reached up to (95.8\%).

On the other hand, the degree of agreement was lower in the studies obtained by Sharma et al., 2017 [19] who found complete agreement of $68.17 \%$ between prenatal and postnatal echo findings and Perriyanayaki et al., 2016 [11] who reported the degree of agreement between pre and postnatal echo findings was $60 \%$.

Limitations of the study were:

Some types of CHDs were not included in the study.

Maternal habitus like obesity and edema of the anterior abdominal wall in case of hypertension or DM, unfavorable fetal lie during examination and excessive fetal movement that may present in some cases due to polyhdraminos may degrade the quality of the study.

Unawareness of clinicians and patients of fetal echocardiography importance for prenatal diagnosis of CHDs.

Limited number of cases.

\section{Conclusion}

From this study, it can be concluded that Fetal echocardiography aims at prenatal diagnosis of CHDs which is instrumental in proper planning of delivery, prenatal care and counseling of parents and due to the high frequency of CHDs within the low risk pregnant females, we suggest that basic fetal echocardiography should be done for all pregnant women regardless the presence of risk factors, at least, the 
four chamber view of the fetal heart should be incorporated into mid-trimester scans, and where feasible, views of the outflow tracts should also be added to increase the diagnostic accuracy of prenatal cardiac scan.

\section{References}

[1] Carvalho JS, AllanLD, Chaoui R, et al. (2013): ISUOG practice guidelines (updated): sonographic screening examination of the fetal heart. Ultrasound ObstetGynecol; 41: 348-359.

[2] Persico N, Moratalla J, Lombardi CM, et al. (2011): Fetal echocardiography at 11-13 weeks by trans-abdominal highfrequency ultrasound. Ultrasound Obstet Gynecol; 37: 296-301.

[3] Bahtiyar MO, Dulay AT, Weeks BP, et al. (2007): Prevalence of congenital heart defects in monochorionic/diamniotic twin gestations: a systematic literature review. J Ultrasound Med; 26: $1491-1498$.

[4] Chen C, Yingliu Y, Yunyun R, et al. (2016): Prenatal diagnosis of CHD by fetal echocardiography in 2nd trimester. Nordic federation of socities of obstertricsand gynecology; 96: 454-463.

[5] Nitin G and Chaubal J. (2017): Fetal echocardiography. Indian J Radiol Imaging; 62: 114-151.

[6] Mottaghi H, Heidari E and Ghiasi SS. (2018): A review study on the prenatal diagnosis of congenital heart disease using fetal echocardiography. Reviews in clinical Medicine; 5: 12-15.

[7] Becker RD. (2006): Detailed screening for fetal anomalies and cardiac defects at the 11-13-week scan. Ultrasound Obstet Gynecol; 27: 613-618.

[8] Carvalho JS, Mavrides E, Shinebourne EA, et al. (2002): Improving the effectiveness of routine prenatal screening for major congenital heart defects. Heart; 88: 387-391.

[9] Radi AE, Abdelkhalek YI, Ali AH, et al. (2018): Role of Fetal Echocardiography in Diagnosis of Fetal Congenital Heart Disease. Nature and Science; 16: 89: 91.

[10] Fernándeza SG, Ramireza JA, Chouzaa MO, et al. (2019): Early fetal ultrasound screening for major congenital heart defects without Doppler. European Journal of Obstetrics, Gynecology and Reproductive Biology; 233: 93-97.

[11] Perriyanayaki BG, Adaikappan $\mathrm{M}$ and Lavanyakumari K. (2016): Role of fetal echocardiography in the detection of congenital heart disease. International Journal of Current Medical and Pharmaceutical Research; 10: 760-771.

[12] Sarkar S, Patra C, Dasgupta MK, et al. (2013): Prevalence of congenital anomalies in neonates and associated risk factors in a tertiary care hospital in eastern India. Journal Clinical Neonatology; 2: 131-134.

[13] Pasierb MM, Penalver JM, Vernon MM, et al. (2018): The role of regional prenatal cardiac screening for congenital heart disease: A single center experience. Congenital Heart Disease; 13: $571-577$.

[14] Cha S, Kim G, Kwon BS, et al. (2012): Recent Trends in Indications of Fetal Echocardiography and Postnatal Outcomes in Fetuses Diagnosed as Congenital Heart Disease. Korean Circ J; 42: 839-844.
[15] Meyer-Wittkopf M, Cooper S and Sholler G. (2001): Correlation between fetal cardiac diagnosis by obstetric and pediatric cardiologist sonographers and comparison with postnatal findings. Ultrasound ObstetGynecol; 17: 392-397.

[16] Tashfeen K and Hamdi IM. (2013): Polyhydramnios as a predictor of adverse pregnancy outcomes. Sultan QaboosUniv Med J; 13: 57-62.

[17] Aly EA and Abd-Manaf MH. (2013): Prevalence and Risk Factors for Major Congenital Anomalies among Egyptian Women: A Four-YearStudy. The Medical Journal of Cairo University; 81: 757-762.

[18] Itsukaichi M, Serikawa T, Yoshihara K, et al. (2018): Effectiveness of fetal cardiac screening for congenital heart disease using a combination of the four-chamber view and three-vessel view during the second trimester scan. J Obstet Gynaecol Res; 44: 49-53

[19] Sharma S, Kaur N, Kaur K, et al. (2017): Role of Echocardiography in Prenatal Screening of Congenital Heart Diseases and its Correlation with Postnatal Outcome. J Clin Diagn Res; 4: 12-14.

[20] Nayak K, Chandra GS, Shetty R, et al. (2016): Evaluation of fetal echocardiography as a routine antenatal screening tool for detection of congenital heart disease. Cardiovascular Diagnosis and Therapy; 6: 44-49.

[21] El Hamid AA, Ismail GM, Eswi AS, et al. (2015): Fetal congenital anomalies among consanguineous and nonconsanguineous marriage pregnant mothers attending Cairo university hospitals. Egyptian Nursing Journal; 10: 1-15.

[22] Luciane A, Edward A, Liliam C, et al. (2014): Prenatal detection of congenital heart diseases: one year survey performing a screening protocol in a single reference center in Brazil. Cardiology Research and Practice; 17: 1-5.

[23] Clur SA, Vanbrussel PM, Mathijssen IB, et al. (2011): Audit of 10 years of referrals for fetal echocardiography. Prenatal Diagnosis; 31: 1134-1140.

[24] Plesinac S, Terzic M, Stimec B, et al. (2007): Value of Fetal Echocardiography in Diagnosis of Congenital Heart Disease in a Serbian University Hospital. Int J FertilWomens Med; 52: $89-92$

[25] Zhang Y, Riehlecolarusso T, Correa A, et al. (2011): Observed prevalence of congenital heart defects from a surveillance study in China. J Ultrasound Med; 30: 989-995.

[26] Calzolari E, Garani G, Cocchi G, et al. (2003): Congenital heart defects: 15 years of experience of the Emilia-Romagna Registry (Italy). Eur J Epidemiol; 18: 773-80.

[27] Ozkutlu S, Akca T, Kafali G, et al. (2010): The results of fetal echocardiography in a tertiary center and comparison of lowand high-risk pregnancies for fetal congenital heart defects. Anatol J Cardiol; 10: 262-269.

[28] Berkley EM, Goens MB, Karr S, et al. (2009): Utility of fetal echocardiography in postnatal management of infants with prenatally diagnosed congenital heart disease. PrenatDiagn; 29: 654-658.

[29] Vanvelzen CL, Clur SA, Rijlaarsdam ME, et al. (2016): Prenatal diagnosis of congenital heart defects: accuracy and discrepancies in a multicenter cohort. Ultrasound ObstetGynecol; 47: 616-622. 
[30] Sokołowski L. (2013): Attitude towards fetal echocardiography among mothers, who gave birth to newborns with congenital heart defect - the survey research. Prenat Cardio; 3: 16-21. 